\title{
Using marine cargo traffic to identify countries in Africa with greatest risk of invasion by Anopheles stephensi
}

Jordan Ahn ${ }^{1,2}$, Marianne Sinka ${ }^{3}$, Seth Irish ${ }^{2,4}$, Sarah Zohdy ${ }^{2,4}$

${ }^{1}$ Rollins School of Public Health, Emory University, Atlanta, GA, USA

${ }^{2}$ Centers for Disease Control and Prevention, Atlanta, GA, USA

${ }^{3}$ Department of Zoology, Oxford University, Oxford, UK

${ }^{4}$ US President's Malaria Initiative, Centers for Disease Control and Prevention, Atlanta, GA, USA 


\section{Abstract}

Anopheles stephensi is an efficient malaria vector commonly found in South Asia and the Arabian Peninsula, but in recent years it has established as an invasive species in the Horn of Africa (HoA). In this region, An. stephensi was first detected in a livestock quarantine station near a major seaport in Djibouti in 2012, in Ethiopia in 2016, in Sudan in 2018 and Somalia in 2019. Anopheles stephensi often uses artificial containers as larval habitats, which may facilitate introduction through maritime trade as has been seen with other invasive container breeding mosquitoes. If An. stephensi is being introduced through maritime traffic, prioritization exercises are needed to identify locations at greatest risk of An. stephensi introduction for early detection and rapid response, limiting further invasion opportunities. Here, we use UNCTAD maritime trade data to 1) identify coastal African countries which were most highly connected to select An. stephensi endemic countries in 2011, prior to initial detection in Africa, 2) develop a ranked prioritization list of countries based on likelihood of An. stephensi introduction for 2016 and 2020 based on maritime trade alone and maritime trade and habitat suitability, and 3) use network analysis to describe intracontinental maritime trade and eigenvector centrality to determine likely paths of further introduction on the continent if An. stephensi is detected in a new location. Our results show that in 2011, Sudan and Djibouti were ranked as the top two countries with likelihood of An. stephensi introduction based on maritime trade alone, and these were indeed the first two coastal countries in the HoA where An. stephensi was detected. Trade data from 2020 with Djibouti and Sudan included as source populations identify Egypt, Kenya, Mauritius, Tanzania, and Morocco as the top five countries with likelihood of An. stephensi introduction. When factoring in habitat suitability, Egypt, Kenya, Tanzania, Morocco, and Libya are ranked highest. Network analysis revealed that the countries with the highest eigenvector centrality scores, and therefore highest degrees of connectivity with other coastal African nations were South Africa (0.175), Mauritius (0.159), Ghana (0.159), Togo (0.157), and Morocco (0.044) and therefore detection of An. stephensi in any one of these locations has a higher potential to cascade further across the continent via maritime trade than those with lower eigenvector centrality scores. Taken together, these data could serve as tools to prioritize efforts for An. stephensi surveillance and control in Africa. Surveillance in seaports of countries at greatest risk of introduction may serve as an early warning system for the detection of An. stephensi, providing opportunities to limit further introduction and expansion of this invasive malaria vector in Africa.

Keywords: malaria, mosquito, shipping, network 


\section{Introduction}

Globalization and the movement of humans and goods has facilitated the introduction of organisms to new locations, and the list of invasive species has grown substantially since the 1980s (Seebens et al., 2020). From 2006 to 2014, the movement of maritime shipping between socio-economic regions, defined as maritime countries grouped by similar socio-economic factors, increased by $258 \%$ with projected growth of maritime movement of 240\% to 1,209\% from 2014 to 2050 (Sardain et al., 2019). However, invasive species are not limited to organisms like zebra mussels (Haag, K. H., 1994), pine and eucalyptus trees (Global Invasive Species Database, 2021; Ritter \& Yost, 2009), and feral hogs (USDA APHIS I History of Feral Swine in the Americas., n.d.). Invasive species can also include arthropod vectors of disease and microbial agents, posing significant public health threats. A prime example is the introduction of Aedes aegypti, the yellow fever mosquito, through the movement of ships in the $19^{\text {th }}$ century to the Americas (Powell et al., 2018). In the $20^{\text {th }}$ century, further movement of cargo ships, in particular those carrying used tires, facilitated the spread of Aedes spp., including Aedes albopictus, a successful invasive species, which is now established on six continents. The proposed mechanisms facilitating the success of Aedes spp. invasion via ships include a few characteristics common to Aedes aegypti mosquitoes: the use of artificial containers as larval habitats, the preference for human blood meals, and the ability for eggs to resist desiccation in the absence of water. This drought tolerance has been proposed as a key explanation for why Aedes species spread efficiently by sea, as less droughttolerant species may require more rapid transportation, such as air travel, for invasive populations to survive long enough to establish in a new location. Other mosquitoes, such as Anopheles mosquitoes, have also created great public health challenges when accidentally introduced to non-native countries such as Egypt and Brazil. Anopheles arabiensis was the cause of malaria outbreaks in Brazil, but was eventually eradicated after challenging and well-coordinated control measures were put in place (Killeen et al., 2002).

Unlike An. arabiensis, Anopheles stephensi, is a unique malaria vector because of its ability to thrive in artificial containers in urban environments. This species is found across South and South-East Asia and the Arabian Peninsula, where it is a primary malaria vector and responsible for both urban and rural malaria transmission. Most malaria vector control efforts in Africa are focused on rural habitats, and 
the ability for malaria vectors to thrive in urban environments may threaten progress made on malaria control and elimination.

In 2012, An. stephensi was first detected on the African continent in a livestock quarantine station in a seaport in Djibouti (Faulde et al., 2014). By 2016, it was then detected in neighboring Ethiopia (Carter et al., 2018). By 2018 (Ahmed et al., 2021) or 2019 (World Health Organization, 2019), An. stephensi was detected near seaports in Sudan, as well as Somalia in 2019 (World Health Organization, 2019). With An. stephensi having unique ecological characteristics and the first detection of the species in seaports, it has been hypothesized that An. stephensi introduction was likely facilitated through maritime trade. Further supporting the similarities between An. stephensi and Ae. aegypti is the fact that in Ethiopia, a large percentage (40\%- Balkew et al. or greater -PMI VL 2021) of the habitats where An. stephensi larvae were detected, Ae. aegypti were also detected. With invasive An. stephensi populations now established in these countries, there is a new threat to malaria control on the African continent. Population genetic analyses suggest the potential source of introduction is South Asia (pre-print by Carter et al. 2021).

The invasion of this malaria vector has the potential to significantly impact global malaria control and elimination efforts (Hamlet et al., 2021). For example, in Djibouti, An. stephensi was linked to malaria outbreaks in 2013 (Faulde et al., 2014) and since its initial detection in Djibouti, malaria cases have increased 30-fold (World Health Organization, 2020). Additionally, although it shows a seasonal variability in abundance in Asia, it has been detected year-round through the hot, dry season in Africa (Seyfarth et al., 2019). Recent laboratory studies on invasive Djiboutian and Ethiopian An. stephensi specimens reveal that, as in Asia, these populations are competent vectors for both Plasmodium vivax and Plasmodium falciparum (Seyfarth, 2019). Thus, countries may need to expand their malaria testing protocol and use of Rapid Diagnostic Tests (RDTs) to detect $P$. vivax in countries where it is less common. Further, field data have shown confirmation of P. vivax sporozoites in An. stephensi in Ethiopia (Tadesse et al., 2021), and high levels of resistance to nearly all insecticides used in malaria vector control (Yared et al., 2020).

Primary malaria vector species are found at lower densities in the urban centers of sub-Saharan Africa, and consequently, these cities tend to have lower malaria transmission rates than surrounding rural areas (Robert et al., 2003). However, a recent habitat suitability modeling study predicted that the 
further invasion of An. stephensi into urban locations on the African continent could put an additional 126 million people at risk of malaria (Sinka et al., 2020).

To address this global challenge and proactively mitigate the threat of An. stephensi, prioritization activities are necessary to identify where this invasive mosquito is likely to be introduced, particularly if this is facilitated by the movement of cargo through marine shipping. To better understand the potential invasion dynamics of An. stephensi, we use United Nations Commerce and Trade (UNCTAD) global data on maritime cargo shipment, including number of shipments, transshipments, cargo volume, and bilateral connectivity, between countries in South Asia and the Arabian Peninsula where An. stephensi is endemic and locations on the African continent where An. stephensi is invasive, as well as all coastal African nations where An. stephensi has not yet been detected. To account for time periods before and after invasion in Africa, data from 2011, 2016, and 2020 were used to identify coastal nations with the highest risk of An. stephensi introduction. These data were then combined with an An. stephensi habitat suitability ranking developed by Sinka et al. (2020).

In this manuscript we describe: 1) data from 2011, prior to the detection of An. stephensi in Djibouti, to determine whether historical maritime connectivity identify Djibouti and Sudan as high risk countries for An. stephensi introduction; 2) a prioritized list of coastal African countries for immediate surveillance based on 2020 data to allow for early detection, rapid response, and limit further introduction of the vector in Africa; and 3) an interactive network model of intracontinental transport routes in Africa allowing for future prioritization hierarchies for surveillance if/when An. stephensi is detected in new locations.

\section{Materials and methods}

\section{Days at sea, habitat suitability index, trade index}

Due to the initial detection of An. stephensi in the port city of Djibouti City, maritime trade data were examined. We ranked the maritime trade connection between countries with known An. stephensi populations (India, Pakistan, Saudi Arabia, and United Arab Emirates) and coastal African countries. Other countries with An. stephensi populations such as Iraq, Iran, and Thailand, exhibited lower trade 
levels and were not included. Additionally, Ethiopia and Somalia were not included despite having confirmed An. stephensi populations due to the absence of UNCTAD maritime traffic data.

We used UNCTAD's Liner Shipping Bilateral Connectivity Index (LSBCI), an index created from trade data from MDS Transmodal (https://www.mdst.co.uk), to measure the amount of connectivity between each pair of countries. The LSBCI factors in five maritime trade indicators. The first is the number of transshipments, when goods are unloaded and moved to another vessel, to get from country $j$ to country $k$. Secondly, LSBCI factors in the number of countries which have direct routes to both countries in the pair (e.g. four countries have direct connections to both country $j$ and country $k$ ). The third indicator is the number of common connections with one transshipment shared between the countries. The level of competition on services that connect the countries, measured by the number of carriers operating on this route, serves as another indicator. Finally, the size of the largest ship on the route with the fewest carriers is considered in calculating LSBCI for a country pair, which can serve as a metric of capacity on sea routes. Each indicator is normalized by subtracting the minimum value from the raw value and dividing by the range. LSBCI is the simple average of the normalized value of these five indicators (Fugazza \& Hoffmann, 2017). This data does not factor in type of vessel or goods, which could influence An. stephensi survivability on board.

We took the LSBCI value and divided it by the number of days required to travel by shipping vessel between the closest and largest ports of the countries. This was calculated via Searoutes which uses the automatic identification system (AIS) of vessels to track them and calculate average time between ports (Searoutes - Making Supply Chains Greener., n.d.). The same vessel speed was used in this calculation to maintain uniformity in measuring distance. This compiled index includes 1) maritime trade degree of connectivity and 2) time between ports (in days) is referred to as the likelihood of An. stephensi introduction through maritime trade index (LASIMTI).

\section{LSBCI / Days between countries = LASIMTI}

Additionally, we incorporated Sinka et al.'s Habitat Suitability Index (HSI), which uses, in order of importance, annual mean temperature, population density, seasonal precipitation, surface wetness, 
vegetation, and other environmental factors to evaluate locations with suitable environments for $A n$. stephensi establishment. Using R (https://www.r-project.org/), a data set of countries was ranked by LASIMTI as well as both LASIMTI and the HSI.

The UNCTAD trade data from three years - 2011, 2016, and 2020 - were chosen. The year 2011 was selected because it was one year prior to the first detection of An. stephensi in the Horn of Africa in Djibouti City. In 2016, An. stephensi was confirmed in Ethiopia, potentially indicating further intracontinental spread or separate introductions. However, Ethiopia is landlocked and therefore was not included in this study. Finally, maritime trade data from 2020 was evaluated to assess further spread along this pathway. Potentially important to note, the UNCTAD estimated that maritime trade fell by $4.1 \%$ in 2020 due to the COVID-19 pandemic. However, they also predicted a rebound of $4.8 \%$ in 2021 (United Nations Conference on Trade and Development, 2021). Additionally, the various types of vessels and goods could influence An. stephensi survivability on board.

Maritime trade data from 2020 was used to create a network model of intracontinental African trade between coastal African countries (Figure 3). The connectivity of coastal African nations was examined based on country pairs' LSBCI. The top three countries, as ranked by LSBCI for each country, were highlighted as links between the nodes. In cases of ties, both countries were included (e.g. Sudan has four country pairs because Egypt, Kenya, and Morocco had the same LSBCI). Another network model was created with a cutoff of 14 days of travel between each node to factor in survivability of $A n$. stephensi during transit (Supplemental Figure 1), assuming An. stephensi are traveling as eggs which hatch upon arrival into a port based on previous literature describing An. stephensi egg resistance to desiccation for nearly two weeks (Chalam 1927). Edges are weighted by the LSBCI value and nodes are weighted by the number of connected countries. Djibouti and Sudan are differentiated due to their established An. stephensi populations. This network model was created with $\mathrm{R}$ in RStudio utilizing the igraph and visNetwork packages.

Network centrality is often calculated with eigenvector centrality, which measures the influence of nodes by factoring in the number of connections and the number of connections of its neighbors. PageRank is a variant of eigenvector centrality but considers the direction of edges. PageRank was used 
for this network model because of the directed, weighted edges. This rank value determines the centrality of a single node in a network based upon how many connections point towards and away from the node as well as each of its neighbors' total number of connections. Edge weights and values of other nodes are factored in as well. The PageRank value is ultimately a probability distribution of the nodes in the network. In this network, this would be if a single vessel was selected, the probability that it would be found at a given node. PageRank was calculated in RStudio with the igraph package.

\section{Results}

Maritime index in 2011 prior to detection of Anopheles stephensi in Africa identified Sudan and Djibouti as highest for risk of introduction

Table 1. Top 10 coastal countries ranked by LASIMTI maritime traffic alone from 2011 UNCTAD maritime trade data

\begin{tabular}{|c|c|c|}
\hline Rank & African Country & Sum of LASIMTI \\
\hline 1 & Sudan & 0.406 \\
\hline 2 & Djibouti & 0.201 \\
\hline 3 & Egypt & 0.188 \\
\hline 4 & Kenya & 0.081 \\
\hline 5 & Tanzania & 0.073 \\
\hline 6 & Morocco & 0.068 \\
\hline 7 & Mauritius & 0.065 \\
\hline 8 & South Africa & 0.057 \\
\hline 9 & Comoros & 0.055 \\
\hline 10 & Mozambique & 0.054 \\
\hline
\end{tabular}

The 2011 Maritime trade data from UNCTAD pointed to Sudan and Djibouti as the top two connected countries to An. stephensi source populations (India, Pakistan, Saudi Arabia, and UAE) when the LASIMTI was summed. The next three countries were Egypt, Kenya, and Tanzania (Table 1, full table: Supplemental Table 1). When HSI was included, the top five countries remained the same (Supplemental Table 2). 
Maritime index in 2016 following detection of Anopheles stephensi in Djibouti and Ethiopia

highlighted Sudan at highest for risk of introduction

The 2016 UNCTAD maritime trade data shown in Supplemental Table 3 highlighted, in order, Sudan, Djibouti, Egypt, Mauritius, and Kenya when ranked by the sum of LASIMTI to the source An. stephensi populations. When this data was ranked first by HSI, the top 5 countries were Sudan, Djibouti, Egypt, Kenya, and Tanzania (Supplemental Table 4)

Anopheles stephensi was established in Djibouti in 2012, so after this date, Djibouti was included as a source population in the calculation, which gave the top five countries as Sudan, Egypt, Mauritius, Kenya, and Tanzania when ranked by their sum of LASIMTI to each source population (Supplemental Table 5). The top five countries when ranked by HSI and then LASIMTI sum were Sudan, Egypt, Kenya, Tanzania, and Morocco when Djibouti was included as a source population (Supplemental Table 6).

Maritime index in 2020 following detection of Anopheles stephensi in Djibouti, Ethiopia, Somalia and Sudan highlighted Kenya, Tanzania, and Mauritius at highest risk of introduction

The 2020 version of these data indicated Sudan, Djibouti, Egypt, Kenya, and Mauritius as the top five connected countries when ranked by the sum of LASIMTI (Supplemental Table 7). Sudan and Djibouti remained the top two connected countries for all the three years examined. The data utilizing both the HSI and LASIMTI placed Sudan, Djibouti, Egypt, Kenya, and Tanzania as the top five countries (Supplemental Table 8).

Table 2. Top 10 coastal countries ranked by LASIMTI maritime traffic alone and LASIMTI and HSI combined using 2020 UNCTAD maritime trade data

\begin{tabular}{|c|c|}
\hline \multicolumn{2}{|c|}{$\begin{array}{l}\text { A. Coastal African Countries Ranked by LASIMTI } \\
\text { alone from } 2020 \text { UNCTAD Maritime Trade Data }\end{array}$} \\
\hline Rank & African Country \\
\hline 1 & Egypt \\
\hline 2 & Kenya \\
\hline 3 & Mauritius* \\
\hline 4 & Tanzania \\
\hline 5 & Morocco \\
\hline
\end{tabular}

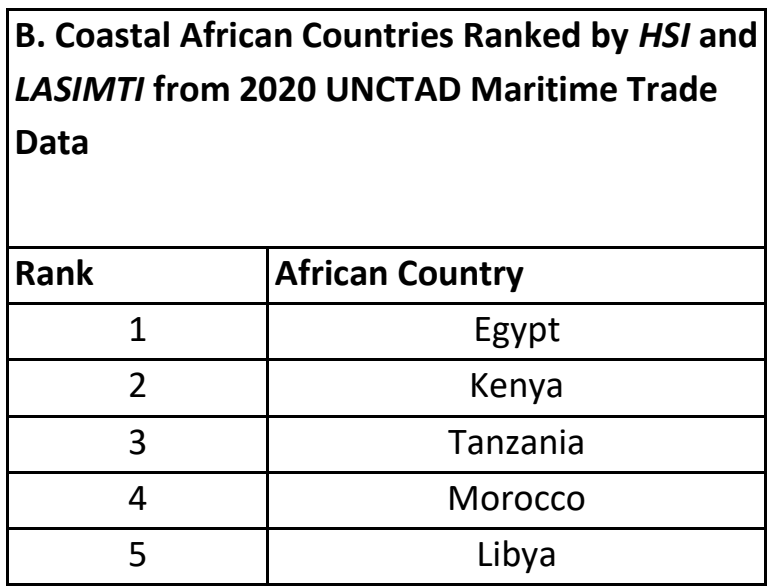




\begin{tabular}{|c|c|}
\hline 6 & South Africa \\
\hline 7 & Libya \\
\hline 8 & Madagascar \\
\hline 9 & Mozambique \\
\hline 10 & Comoros* \\
\hline
\end{tabular}

\begin{tabular}{|c|c|}
\hline 6 & Madagascar \\
\hline 7 & Mozambique \\
\hline 8 & Angola \\
\hline 9 & Senegal \\
\hline 10 & Congo \\
\hline
\end{tabular}

A. Top 10 Countries based on LASIMTI from 2020 UNCTAD data (left)

B. Top 10 Countries based on HSI and LASIMTI from 2020 UNCTAD data (right)

* No HSI data were available for these countries, which may contribute to their drop in ranking when HSI and LASIMTI were combined in Table 2B.

Since An. stephensi populations have been confirmed in Sudan in 2018 or 2019, these data were further examined with Djibouti and Sudan included as potential source populations for An. stephensi (WHO, 2019). With Djibouti and Sudan included as source populations while calculating LASIMTI, the top five countries at risk of An. stephensi introduction were Egypt, Kenya, Mauritius, Tanzania, and Morocco (Table 2A). When the HSI was also included in the ordering, the top five countries were Egypt, Kenya, Tanzania, Morocco, and Libya (Table 2B). Full tables can be found in the supplemental material (Supplemental Tables 9 and 10, respectively)

\section{Intracontinental connectivity network model}

The interactive network model reveals degrees of connectivity within coastal nations on the African continent. Specifically, it highlights highly connected coastal African countries such as South Africa as well as the Western African nations. Utilizing the PageRank centrality score, South Africa (0.175), Mauritius (0.159), Ghana (0.159), Togo (0.157), and Morocco (0.044) were more highly connected to coastal countries in Africa than others via maritime trade in this network (Supplemental Table 11). Djibouti and Sudan were ranked 7th (0.030) and 32nd (0.0045) respectively. Egypt was highlighted often as being at risk of introduction by the LASIMTI ranking. In the PageRank centrality analysis, Egypt was ranked 6th with a rank value of 0.0353. Other countries that were highlighted are Kenya (11th, 0.0164) and Tanzania (12th, 0.0156).

\section{Discussion}

With human movement and globalization, invasive container breeding mosquitoes capable of transmitting dengue, Zika, chikungunya and now malaria, with An. stephensi, are being introduced and 
establishing populations in new locations. They are bringing with them the threat of increased risk of vector-borne diseases to new locations where health systems may not be prepared.

Anopheles stephensi was first detected on the African continent in Djibouti in 2012 and has since been confirmed in Ethiopia, Somalia, and Sudan. Unlike most malaria vectors, An. stephensi is often found in artificial containers and in urban settings. Additionally, historical reports show that An. stephensi eggs are able to resist desiccation in soil for up to 14 days (Chalam, 1927). This unique ecology combined with its initial detection in seaports in Djibouti, Somalia, and Sudan has led scientists to believe that the movement of this vector is likely facilitated through maritime trade.

By modeling inter- and intra-continental maritime connectivity in Africa, we identified a ranking of likelihood of An. stephensi introduction if facilitated through maritime movement. Anopheles stephensi was not detected in Africa (Djibouti) until 2012. To determine whether historical maritime data would have identified the first sites of introduction, 2011 maritime data were analyzed to determine whether the sites with confirmed An. stephensi would rank highly in connectivity to An. stephensi endemic countries. Using 2011 data on maritime connectivity alone, Djibouti and Sudan were identified as the top two countries at risk of An. stephensi introduction facilitated by marine cargo shipments. In 2021, these are two of the three African coastal nations where An. stephensi is confirmed to be established.

When 2011 maritime data were combined with the HSI for An. stephensi establishment, the top five countries remained the same as with maritime data alone: Sudan, Djibouti, Egypt, Kenya and Tanzania. The maritime data showed the likelihood of introduction, and HSI showed the likelihood of establishment. When combined, the analyses showed a likelihood of being able to establish and survive once introduced. Interestingly, the results of the combined analyses aligned with the detection data being reported in the Horn of Africa. The 2011 maritime data reinforced the validity of the model as it pointed to Sudan and Djibouti as highest risk, and those were the two countries where An. stephensi initially established in the following years. Similarly, the HSI data for Ethiopia aligned closely with detections of the species to date (Balkew et al. 2021). Interestingly, around this time of initial detection in Djibouti, Djibouti City port underwent development and organizational change. The government of Djibouti took back administrative control of the port as early as 2012 due disputes with the previous port controller (Port History - PORT DE DJIBOUTI, n.d.). The development and construction could 
have been created environments for the establishment of An. stephensi. Additionally, the change of hand might have made it easier for this to go unnoticed.

Following this method, the maritime trade data from 2020 highlighted countries at risk of An. stephensi introduction from endemic countries as well as from the coastal African countries with newly introduced populations. We provided a prioritized list of countries for the early detection, rapid response, and targeted surveillance of An. stephensi in Africa based on these data and the HSI. Further invasion of An. stephensi on the African continent has the potential to reverse progress made on malaria control in the last century and divert resources from rural to urban settings which could worsen the situation. Anopheles stephensi thrives in urban settings and in containers, in contrast to the rural settings and natural habitats where most Anopheles spp. are found (Seyfarth, 2019). The situation in Djibouti may be a harbinger for what is to come if immediate surveillance and control strategies are not initiated in the countries identified at highest risk (Hamlet et al., 2021).

Maritime data from 2020, with Djibouti and Sudan considered as potential source populations for intracontinental introduction of An. stephensi, indicated the top five vulnerable countries were Egypt, Kenya, Mauritius, Tanzania, and Morocco. Targeted larval surveillance in these countries near seaports may provide a better understanding of whether there are maritime introductions. When the 2020 maritime data was combined with HSI for An. stephensi, the top five countries were instead Egypt, Kenya, Tanzania, Morocco, and Libya. Interestingly, historical reports of An. stephensi in Egypt exist; however, following further identification, these specimens were determined to be An. ainshamsi (Gad et al. 2006). With several suitable habitats both along the Egyptian coast and inland, revisiting surveillance efforts there would provide insight into how countries that are highly connected to $A n$. stephensi-endemic locations through maritime traffic may experience introductions.

Further field validation of this prioritized list is necessary, because it is possible that An. stephensi is being introduced through other transportation routes, such as land transport hubs or airports (Tatem et al. 2006), or may even be dispersed through wind facilitation (Huestis et al., 2019). However, countries highlighted here with high levels of connectivity to known An. stephensi locations should be considered at high risk of introduction. Vector and malaria case surveillance should be urgently established to determine whether An. stephensi introduction has already occurred. Primary surveillance for both Aedes 
aegypti and An. stephensi are through larval surveys, and the two mosquitoes are commonly detected in the same larval habitats. It could therefore be beneficial to coordinate with existing Aedes surveillance efforts to be able to simultaneously gather data on medically relevant Aedes vectors while seeking to determine whether An. stephensi is present. Similarly, in locations with known An. stephensi without well-established Aedes programs, coordinating larval surveillance efforts would provide an opportunity to conduct malaria and arboviral vector surveillance simultaneously.

Efforts to map key points of introduction based on the movement of goods and people could provide high specificity for targeted surveillance and control efforts. For example, participatory mapping or population mobility data collection methods, such as those used to determine routes of human movement for malaria elimination, may simultaneously provide information on where targeted $A n$. stephensi surveillance efforts should focus. Several methods have been proposed in the literature for modeling human movement and one in particular, PopCAB, which is often used for communicable diseases, combined quantitative and qualitative data with geospatial information to identify points of control (Merrill et al., 2021).

Data on invasive mosquito species have shown that introduction events are rarely a one-time occurrence. Population genetics data on Aedes species indicate that reintroductions are very common and can facilitate the movement of genes between geographically distinct populations, raising the potential for introduction of insecticide resistance, thermotolerance, and other phenotypic and even behavioral traits which may be facilitated by gene flow and introgression (Yared et al. 2020). Djibouti, Sudan, Somalia, and Ethiopia, countries with established invasive populations of An. stephensi, should continue to monitor invasive populations and points of introduction to control and limit further expansion and adaptation of An. stephensi. Work by Carter et al. 2021 (pre-print) has shown that $A n$. stephensi populations in Ethiopia in the north and central regions can be differentiated genetically, potentially indicating that these populations are a result of more than one introduction into Ethiopia from South Asia, further emphasizing the potential role of anthropogenic movement on the introduction of the species (Carter et al. 2021).

One major limitation of this work is that Somalia is the third coastal nation where An. stephensi has been confirmed; however, marine traffic data were not available for Somalia so it could not be included 
in this analysis. The potential impact of Somalia on maritime trade is unknown and it should not be excluded as a potential source population. Other countries with An. stephensi populations, such as Iran, Myanmar, and Iraq, constitute lower relative percentages of trade with these countries so were not included in the analysis. However, genetic similarities were noted between An. stephensi in Ethiopia and Pakistan, so this nation was included (Carter et al., 2018).

Due to the nature of maritime traffic, inland countries, such as Ethiopia, were also not included in this prioritized ranking. Countries which are inland but share borders with high-risk countries according to the LASTIMI index should also be considered with high priority. For example, the ranking from 2011 highlights Sudan and Djibouti, both which border Ethiopia, and efforts to examine key international land transportation routes may provide additional insight into the expansion routes of this invasive species.

In Ethiopia, An. stephensi was detected in 2016. It has largely been detected along major transportation routes, although further data are needed to understand this association since most sampling sites have also been located along major transport routes. Importantly, Ethiopia relies heavily on the ports of Djibouti and Somalia for maritime imports and exports. Surveillance efforts have revealed that $A n$. stephensi is also frequently associated with livestock shelters and are frequently found with livestock bloodmeals (Balkew et al., 2021). The original detection of An. stephensi was found in a livestock quarantine station in the port of Djibouti. Additionally, livestock constitutes one of the largest exports of maritime trade from this region. For countries with high maritime connectivity to An. stephensi locations but where An. stephensi has not been detected, surveillance efforts near seaports, in particular those with livestock trade, is encouraged for early detection of this invasive species.

While not explicitly analyzed in this study, future examination of the movement of specific goods would be beneficial in interpreting potential An. stephensi invasion pathways. As Ae. aegypti and Culex coronator were detected in tires or Ae. albopictus through the tire and bamboo (Dracaena sanderiana) trade, An. stephensi could be carried through maritime trade of specific goods (Higa et al., 2010, Scholte et al., 2008, Yee et al., 2012). Petroleum and oil constitute the largest portion of imports to African nations with established An. stephensi populations from the Arabian Peninsula. The second largest group of imports are cars and car parts which could include tires. These African countries primarily 
exported livestock, coffee, and other agricultural goods (Simoes \& Hidalgo, 2011). From the source populations in South Asia, imports to the four African countries with confirmed Anopheles stephensi were mainly sugar, textiles, and medicines. Car-related goods including tires were also fairly common imports to these African countries. Exports to South Asian countries consisted of seeds and other agricultural goods as well as crude petroleum. Among the top countries highlighted by the LASIMTI ranking, Djibouti and Sudan imported relatively more sugar and sugar confectionery than Kenya and Tanzania from source population countries in 2019. In 2011, prior to detection of An. stephensi, sugar was the highest reported import to Djibouti from these countries.

Egypt, one of the countries that was highlighted in the LASIMTI ranking, imports almost entirely livestock and seeds from the four African countries with known invasive An. stephensi populations and exports petroleum, chemical products, and vegetable products. From these same countries, Tanzania and Kenya import large amounts of vehicles while vegetable products also make up a large proportion Kenya's imports. Mauritius imports mainly precious stones and coffee from the African countries with An. stephensi.

Various types of vessels are used to transport certain cargo such as container, bulk, and livestock ships. These vessels could affect An. stephensi survivability during transit. Sugar and grain are often shipped in bulk or break bulk vessels which store cargo in large unpackaged containers. Container ships transport products stored in containers sized for land transportation via trucks and carry goods such as tires (UN Conference on Trade and Development, 2018). Livestock vessels are often multilevel, openair ships which require more hands working on deck and water management (How is Livestock Transportation Done Using Livestock Carriers?, 2019).

Using LSBCI index data from 2020, we developed a network to highlight how coastal African nations are connected to through maritime trade. The role of this network analysis was two-fold, 1) it demonstrated intracontinental maritime connectivity; and 2) it highlighted the top three countries connected via maritime trade through an interactive HTML model (Supplemental File). For example, if An. stephensi is detected and established in a specific coastal African nation such as Djibouti, selecting the Djibouti node reveals the top three locations at risk of introduction from that source country 
(Djibouti links to Sudan, Egypt and Kenya). This can be used as an actionable prioritized list for surveillance if An. stephensi is detected in any given country and highlights major maritime hubs in Africa which could be targeted for surveillance and control.

The network analysis revealed the significance of South African trade to the rest of the continent. Due to the distance, South Africa did not appear to be at high risk of An. stephensi introduction. However, this analysis revealed that if An. stephensi were to enter nearby countries, it could very easily be introduced because of its high centrality. Western African countries such as Ghana, Togo, and Morocco are also heavily connected to other parts of Africa. Interestingly, Mauritius appears to be highly significant to this network of African maritime trade. Based on 2020 maritime data, Mauritius was ranked as the country with the third greatest likelihood of introduction of An. stephensi and also had the second highest centrality rank value of 0.159. Considering these factors, Mauritius could serve as an important port of call connecting larger ports throughout Africa or other continents. If An. stephensi were to become established in countries with high centrality ranks, further expansion on the continent could be accelerated drastically. These ports could serve as important watchpoints and indicators of An. stephensi's incursion into Africa.

Anopheles stephensi is often found in shared habitats with Aedes spp. and an important opportunity exists to leverage Aedes surveillance efforts to detect invasive An. stephensi, especially in countries that have high potential of introduction through maritime trade. For example, the island of Mauritius ranks third most connected to An. stephensi locations based on 2020 maritime data. With long standing regular larval surveillance efforts across the island for Aedes spp., this island nation is well suited to look for Anopheles larvae as part of Aedes surveillance efforts for early detection and rapid response to prevent the establishment of An. stephensi.

\section{Conclusions}

With increases in globalization and the volume and frequency of marine cargo traffic connecting countries and continents, information on maritime connectivity can serve as an early warning system for invasive species in general, including those relevant to public health. We show that maritime data prior to the detection of An. stephensi in Africa identified Djibouti and Sudan as countries at greatest 
risk of introduction, and these are locations where invasive An. stephensi populations are now established. Using more recent data we present a prioritized list of countries at risk of An. stephensi introduction through maritime traffic and describe intracontinental maritime connectivity. These data highlight the potential use of maritime trade data to guide intensified surveillance efforts for the early detection of invasive mosquito vectors, such as An. stephensi in Africa, to limit establishment and impact on public health.

Through integrated vector management, existing Aedes programs could be leveraged by providing training for An. stephensi identification. The distinct larval characteristics of Ae. aegypti and An. stephensi suggest that as part of Aedes surveillance, the simple addition of also looking for An. stephensi larvae can provide opportunities to search for the invasive malaria vector without needing to establish new programs. Similarly, in locations where An. stephensi surveillance is ongoing, the addition of data collection on Aedes spp. could also be included. These integrated efforts will strengthen local, regional, and national entomological surveillance systems for vector borne diseases. 
bioRxiv preprint doi: https://doi.org/10.1101/2021.12.07.471444; this version posted December 10,2021 . The copyright holder for this preprint (which was not certified by peer review) is the author/funder, who has granted bioRxiv a license to display the preprint in perpetuity. It is made available under aCC-BY-NC-ND 4.0 International license.

\section{Figures}

Figure 1. These 2020 heat maps rank coastal African countries using (A) LASIMTI data alone and (B) LASIMTI and HSI combined, based on maritime connectivity to countries where An. stephensi is endemic. Higher ranking countries which are at greater risk of $A n$. stephensi introduction are darker in red color than those that are lower ranking (lighter red). Countries which are shaded grey are inland countries that do not have a coast or there is no data on maritime movement available. Of those countries without data, Ethiopia and Somalia have confirmed An. stephensi populations. Countries which are grey and patterned have established or endemic An. stephensi populations and are considered to be source locations for potential An. stephensi introduction in this analysis.
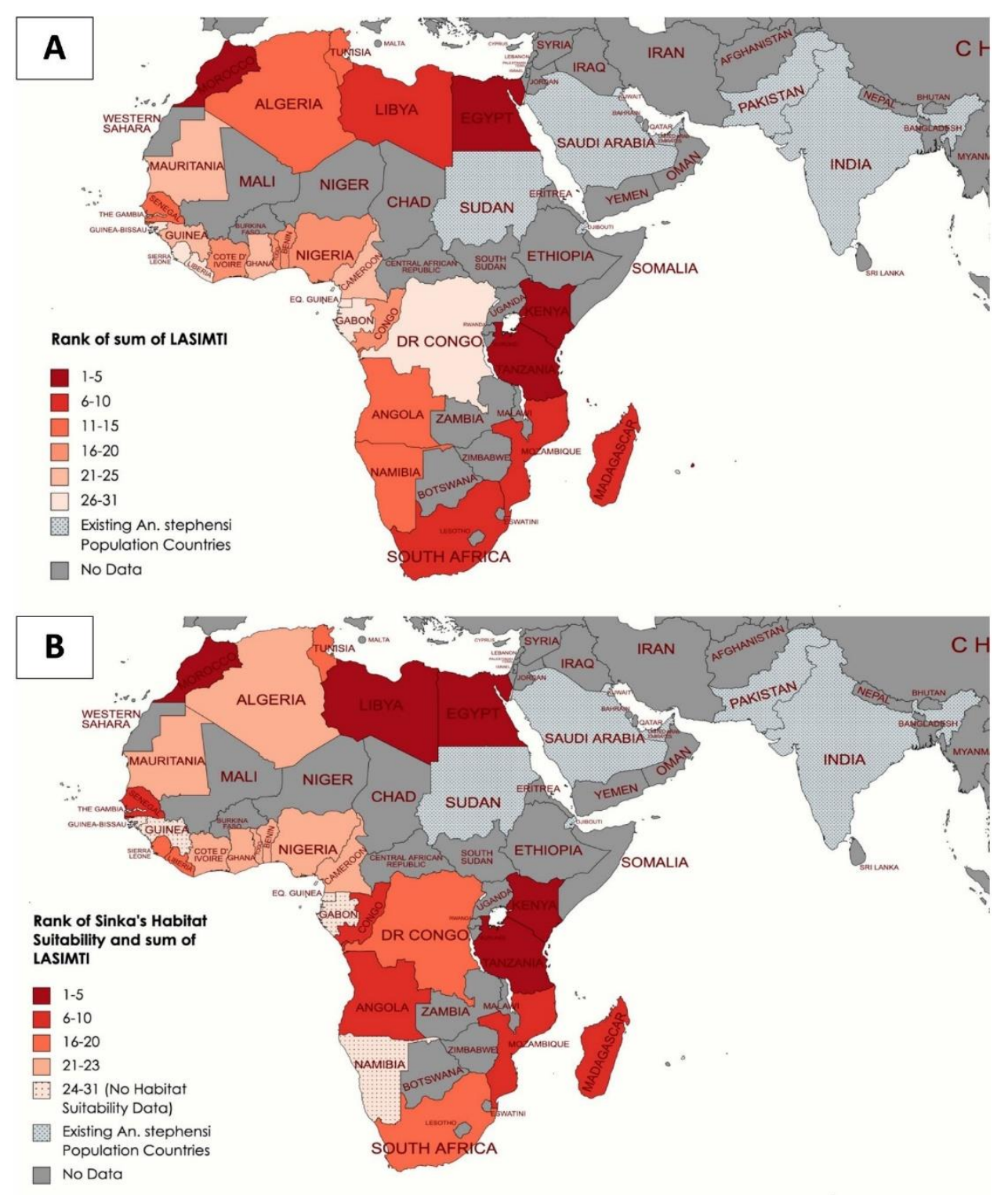
bioRxiv preprint doi: https://doi.org/10.1101/2021.12.07.471444; this version posted December 10, 2021. The copyright holder for this preprint (which was not certified by peer review) is the author/funder, who has granted bioRxiv a license to display the preprint in perpetuity. It is made available under aCC-BY-NC-ND 4.0 International license.

Figure 2. The sum of each LASIMTI for coastal African countries with inputs from endemic An. stephensi countries sorted in descending order and arranged by year to highlight highly connected countries and overall maritime traffic growth. This graph breaks down the LASIMTI ranking by country by year. Each column is sorted by count LASIMTI sum. This shows that overall maritime trade between endemic An. stephensi countries and coastal Africa has increased over time. This also highlights Sudan, Djibouti, Egypt, Mauritius, Kenya, and Tanzania as highly connected countries.

Sum of LASIMTI with An. stephensi Countries by Year

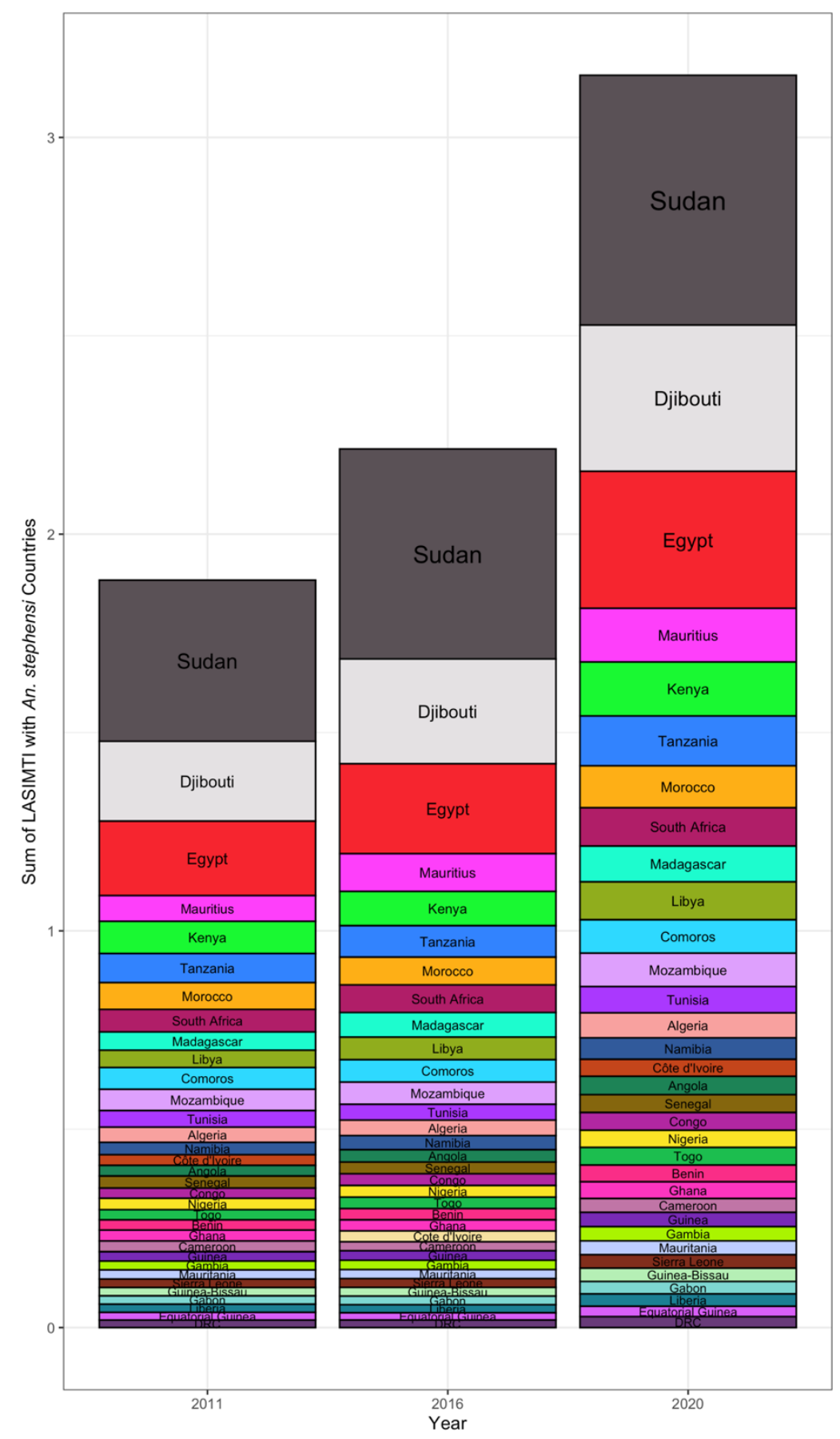


bioRxiv preprint doi: https://doi.org/10.1101/2021.12.07.471444; this version posted December 10, 2021. The copyright holder for this preprint (which was not certified by peer review) is the author/funder, who has granted bioRxiv a license to display the preprint in perpetuity. It is made available under aCC-BY-NC-ND 4.0 International license.

Figure 3. LASIMTI of coastal African countries in 2020 shows heterogeneity across the continent in maritime movement into ports. A) Relatively high traffic from countries where An. stephensi is endemic to Egypt, Djibouti, and Sudan. B) Visualization of the volume of traffic into Djibouti and Sudan in 2019 (modified from marinetraffic.com) shows that a few ports in these two countries accommodate hundreds of thousands of transport routes each year.

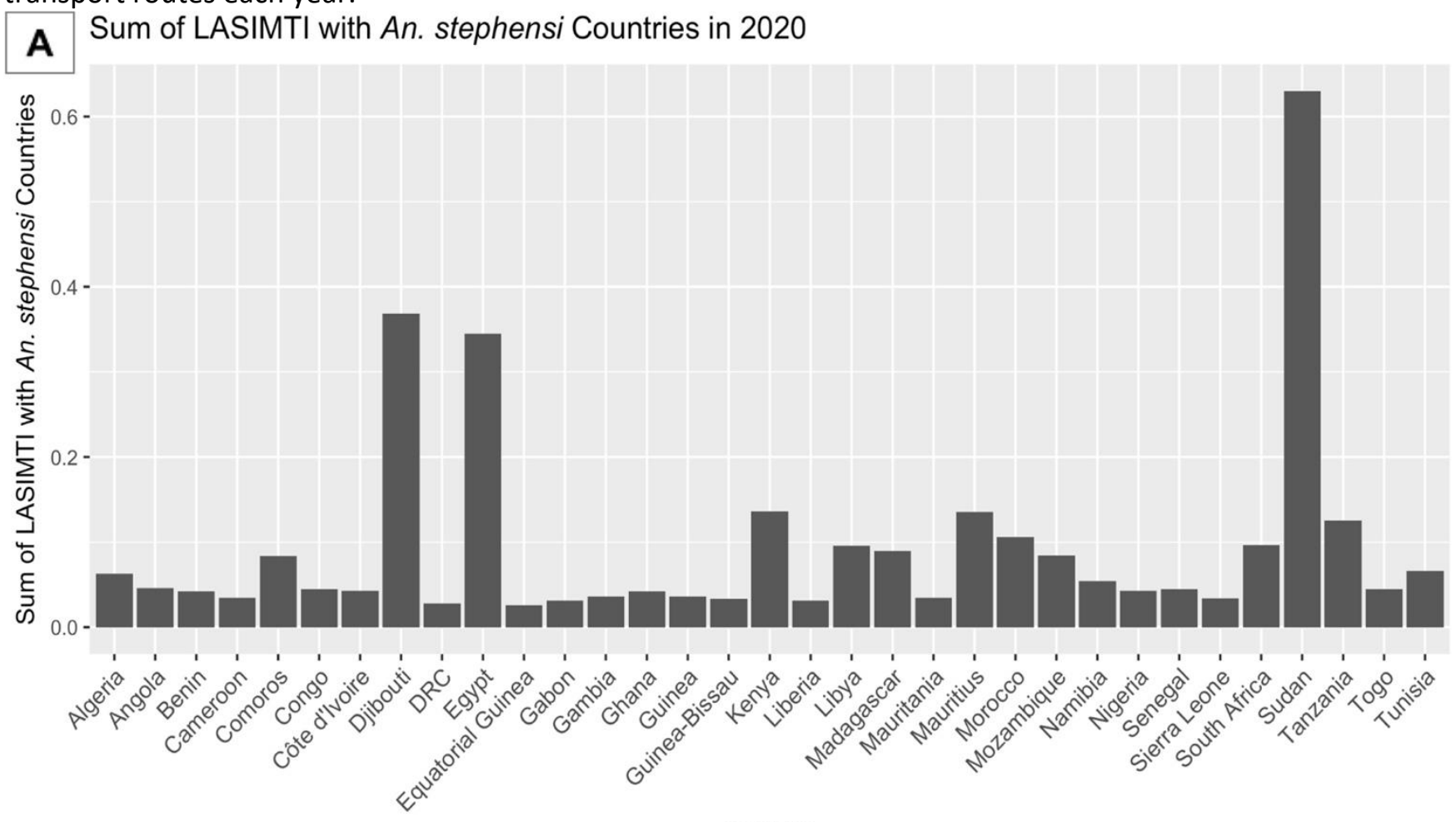

Country

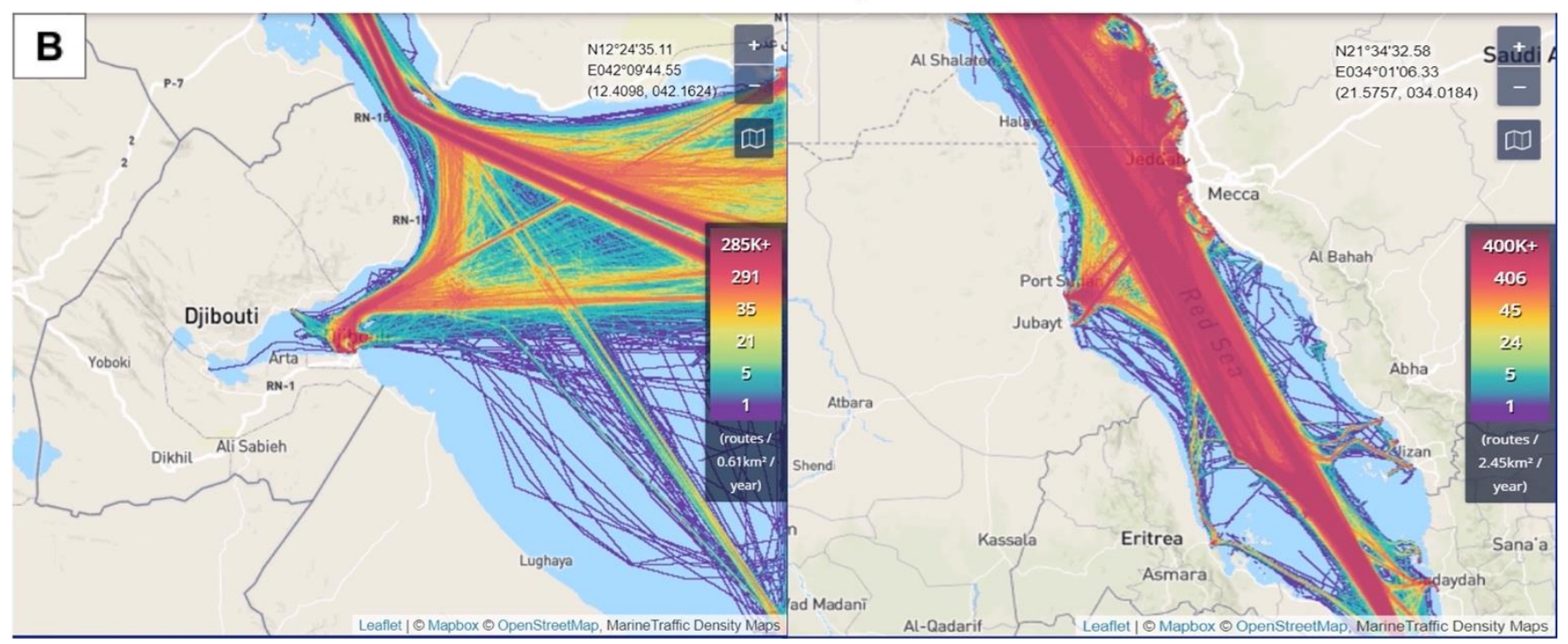


bioRxiv preprint doi: https://doi.org/10.1101/2021.12.07.471444; this version posted December 10,2021 . The copyright holder for this preprint (which was not certified by peer review) is the author/funder, who has granted bioRxiv a license to display the preprint in perpetuity. It is made available under aCC-BY-NC-ND 4.0 International license.

Figure 4. Directed network model of coastal African nations connected through ranking LSBCl data with Sudan and Djibouti highlighted as having known An. stephensi populations. This network model was produced using the 2020 UNCTAD trade index, LSBCl. Each node represents a coastal African country with directed edges pointing towards another node. A connection indicates an $\mathrm{LSBCl}$ ranked as one of the origin node's highest three $\mathrm{LSBCl}$. The nodes are also weighted by the number of connections directed towards it as shown by the size. The red diamond nodes (Djibouti and Sudan) are countries with known An. stephensi populations. (Interactive HTML link found in supplement)
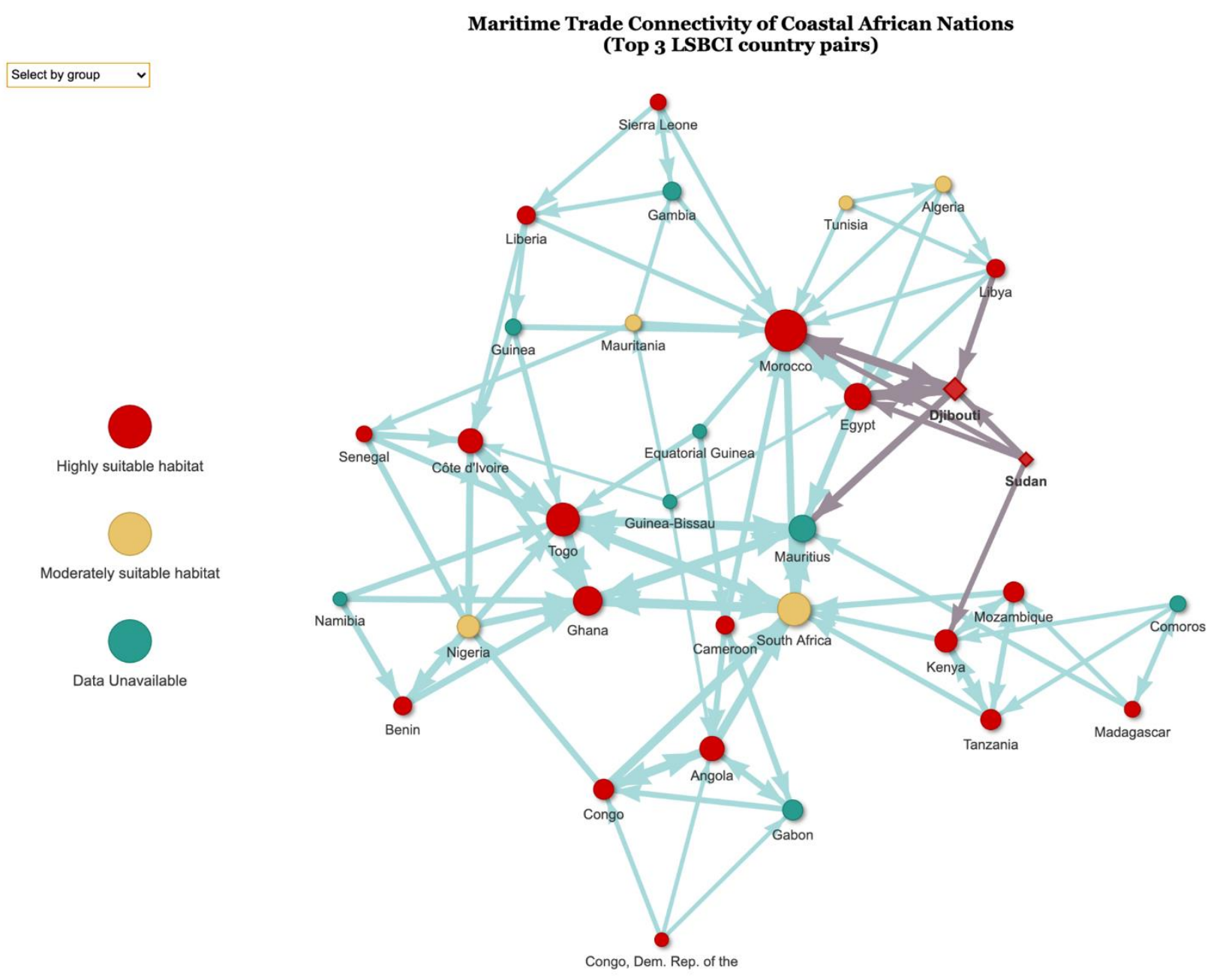


\section{References}

Ahmed, A., Khogali, R., Elnour, M.-A. B., Nakao, R., \& Salim, B. 2021. Emergence of the invasive malaria vector Anopheles stephensi in Khartoum State, Central Sudan. Parasites $\mathcal{E}$ Vectors, 14(1), 511. https://doi.org/10.1186/s13071-021-05026-4

Ammar, S. E., Mclntyre, M., Swan, T., Kasper, J., Derraik, J. G. B., Baker, M. G., \& Hales, S. 2019. Intercepted Mosquitoes at New Zealand's Ports of Entry, 2001 to 2018: Current Status and Future Concerns. Tropical Medicine and Infectious Disease, 4(3), 101. https://doi.org/10.3390/tropicalmed4030101

Balkew, M., et al. 2021. Geographical distribution of Anopheles stephensi in eastern Ethiopia. Parasites $\mathcal{E}$ Vectors, 13(1): p. 35.

Balkew, M., Mumba, P., Yohannes, G. et al. 2021. An update on the distribution, bionomics, and insecticide susceptibility of Anopheles stephensi in Ethiopia, 2018-2020. Malaria Journal. 20, 263. https://doi.org/10.1186/s12936-021-03801-3

Beyond 20/20 WDS - Summary. (n.d.). Retrieved July 20, 2021, from https://unctadstat.unctad.org/wds/TableViewer/summary.aspx?ReportId=96618

Carter, T.E., Yared, S., Gebresilassie, A., Bonnell, V., Damodaran, L., Lopez, K., Ibrahim, M., Mohammed, S., Janies, D. 2018. First detection of Anopheles stephensi Liston, 1901 (Diptera: Culicidae) in Ethiopia using molecular and morphological approaches. Acta Tropica, 188: p. 180-186. https://doi.org/10.1016/j.actatropica.2018.09.001

Carter, T. E., Yared, S., Getachew, D., Spear, J., Choi, S. H., Samake, J. N., Mumba, P., Dengela, D., Yohannes, G., Chibsa, S., Murphy, M., Dissanayake, G., Flately, C., Lopez, K., Janies, D., Zohdy, S., Irish, S. R., \& Balkew, M. 2021. Tracking of Anopheles stephensi in Ethiopia using mitochondrial DNA reveals pattern of spread. BioRxiv, 2021.04.07.437873. https://doi.org/10.1101/2021.04.07.437873 
Chalam, B. S. 1927. The Resistance of Anopheles Eggs to Desiccation. Indian Journal of Medical Research, 14(4).

Coetzee, M. 2020. Key to the females of Afrotropical Anopheles mosquitoes (Diptera: Culicidae). Malaria Journal, 19: 1-20. https://doi.org/10.1186/s12936-020-3144-9

Enayati, A., Hanafi-Bojd, A.A., Sedaghat, M.M., Zaim, M., Hemingway, J. 2020. Evolution of insecticide resistance and its mechanisms in Anopheles stephensi in the WHO Eastern Mediterranean Region. Malaria Journal, 19, 258. https://doi.org/10.1186/s12936-02003335-0

Ethiopian Public Health Institute (EPHI). 2016. Ethiopia National Malaria Indicator Survey 2015. 110pp.

Faulde, M.K., Rueda, L.M., Kaireh, B.A. 2014. First record of the Asian malaria vector Anopheles stephensi and its possible role in the resurgence of malaria in Djibouti, Horn of Africa. Acta Tropica, 139: 39-43.

Gad, A.M., Harbach, R.E., \& Harrison, B.A. 2006. Anopheles (Cellia) ainshamsi, n. sp. (Diptera: Culicidae), a saltwater species from the Red Sea coast of Egypt. Proceedings of the Entomological Society of Washington, 108(2), 366-380.

Global Invasive Species Database. 2021. Species profile: Pinus. Downloaded from http://www.iucngisd.org/gisd/species.php?sc=890 on 20-07-2021.

Haag, K. H. (1994). Zebra mussels in the eastern United States. In Fact Sheet (No. 014-94). U.S. Geological Survey. https://doi.org/10.3133/fs01494

Hamlet, A., Dengela, D., Tongren, J. E., Tadesse, F. G., Bousema, T., Sinka, M., Seyoum, A., Irish, S. R., Armistead, J. S., \& Churcher, T. 2021. The potential impact of Anopheles stephensi establishment on the transmission of Plasmodium falciparum in Ethiopia and prospective control measures. MedRxiv. https://doi.org/10.1101/2021.08.19.21262272

Higa, Y., Yen, N. T., Kawada, H., Son, T. H., Hoa, N. T., \& Takagi, M. 2010. Geographic Distribution of Aedes aegypti and Aedes albopictus Collected from Used Tires in Vietnam. 
Journal of the American Mosquito Control Association, 26(1), 1-9. https://doi.org/10.2987/095945.1

How is Livestock Transportation Done Using Livestock Carriers? (2019, January 26). Marine Insight. https://www.marineinsight.com/types-of-ships/how-is-livestock-transportationdone-using-livestock-carriers/

Huestis, D. L., Dao, A., Diallo, M., Sanogo, Z. L., Samake, D., Yaro, A. S., Ousman, Y., Linton, Y.-M., Krishna, A., Veru, L., Krajacich, B. J., Faiman, R., Florio, J., Chapman, J. W., Reynolds, D. R., Weetman, D., Mitchell, R., Donnelly, M. J., Talamas, E., ... Lehmann, T. 2019. Windborne long-distance migration of malaria mosquitoes in the Sahel. Nature, 574(7778), 404-408. https://doi.org/10.1038/s41586-019-1622-4

Killeen, G. F., Fillinger, U., Kiche, I., Gouagna, L. C., \& Knols, B. G. 2002. Eradication of Anopheles gambiae from Brazil: Lessons for malaria control in Africa? The Lancet Infectious Diseases, 2(10), 618-627. https://doi.org/10.1016/S1473-3099(02)00397-3

Merrill, R. D., Chabi, A. I. B., McIntyre, E., Kouassi, J. V., Alleby, M. M., Codja, C., Tante, O., Martial, G. T. P., Kone, I., Ward, S., Agbeko, T. T., \& Kaka1, C. G. 2021. An approach to integrate population mobility patterns and sociocultural factors in communicable disease preparedness and response. Humanities and Social Sciences Communications, 8(1), 1-11. https://doi.org/10.1057/s41599-020-00704-7

PMI VectorLink Ethiopia Project. Final Entomology Report. May 2019-March 2020. 2020.

Powell, J. R., Gloria-Soria, A., \& Kotsakiozi, P. 2018. Recent History of Aedes aegypti: Vector Genomics and Epidemiology Records. BioScience, 68(11), 854-860. https://doi.org/10.1093/biosci/biy119

Ritter, M., \& Yost, J. (2009). Diversity, reproduction, and potential for invasiveness of eucalyptus in California. Madroño, 56(3), 155-167.

Sardain, A., Sardain, E., \& Leung, B. 2019. Global forecasts of shipping traffic and biological invasions to 2050. Nature Sustainability, 2(4), 274-282. https://doi.org/10.1038/s41893-0190245-y 
Schmidt, T. L., Chung, J., Rooyen, A. R. van, Sly, A., Weeks, A. R., \& Hoffmann, A. A. (2020). Incursion pathways of the Asian tiger mosquito (Aedes albopictus) into Australia contrast sharply with those of the yellow fever mosquito (Aedes aegypti). Pest Management Science, 76(12), 4202-4209. https://doi.org/10.1002/ps.5977

Scholte, E.-J., Dijkstra, E., Blok, H., Vries, A. D., Takken, W., Hofhuis, A., Koopmans, M., Boer, A. D., \& Reusken, C. B. E. M. (2008). Accidental importation of the mosquito Aedes albopictus into the Netherlands: A survey of mosquito distribution and the presence of dengue virus. Medical and Veterinary Entomology, 22(4), 352-358.

https://doi.org/10.1111/j.1365-2915.2008.00763.x

Seebens, H., Bacher, S., Blackburn, T.M., Capinha,C., Dawson, W., Dullinger, S., Genovesi, P., Hulme, P.E., van Kleunen, M., Kühn, I., Jeschke, J.M., Lenzner, B., Liebhold, A.M., Pattison, Z., Pergl, J., Pyšek, P., Winter, M., Essl, F. 2020. Projecting the continental accumulation of alien species through to 2050. Global Change Biology, 27: 970-982. https://doi.org/ 10.1111/gcb.15333.

Seyfarth, M., Kaireh, B.Aa, Abdi, A.A., Bouh, S.M., Faulde, M.K. 2019. Five years following first detection of Anopheles stephensi (Diptera: Culicidae) in Djibouti, Horn of Africa: populations established - malaria emerging. Parasitology Research, 118:725-732.

Simoes, A., \& Hidalgo, C. (2011). The Economic Complexity Observatory: An Analytical Tool for Understanding the Dynamics of Economic Development. In AAAI Workshops. Retrieved from https://www.aaai.org/ocs/index.php/WS/AAAIW11/paper/view/3948/4325

Sinka, M.E., Bangs, M.J., Manguin, S., Chareonviriyaphap, T., Patil, A.P., Temperley, W.H., et al. 2011. The dominant Anopheles vectors of human malaria in the Asia-Pacific region: occurrence data, distribution maps and bionomic précis. Parasites $\mathcal{E}$ Vectors, 4:89-10. https://doi.org/10.1186/1756-3305-4-89

Sinka, M.E., Pironon, S., Massey, N.C., Longbottom, J., Hemingway, J., Moyes, C.L., Willis, K.J. 2020. A new malaria vector in Africa: Predicting the expansion range of Anopheles 
stephensi and identifying the urban populations at risk. Proceedings of the National Academy of Sciences, 117(40): 24900-24908.

Sukehiro, N., Kida, N., Umezawa, M., Murakami, T., Arai, N., Jinnai, T., Inagaki, S., Tsuchiya, H., Maruyama, H., \& Tsuda, Y. (2013). First Report on Invasion of Yellow Fever Mosquito, Aedes aegypti, at Narita International Airport, Japan in August 2012. Japanese Journal of Infectious Diseases, 66(3), 189-194. https://doi.org/10.7883/yoken.66.189

Tadesse, F.G., Ashine, T., Teka, H., Esayas, E., Messenger, L.A., Chali, W., et al. 2021. Anopheles stephensi Mosquitoes as Vectors of Plasmodium vivax and falciparum, Horn of Africa, Emerging Infectious Diseases, 27:603-607. https://dx.doi.org/10.3201/eid2702.200019

Tatem, A.J., Rogers, D.J. \& Hay, S.I. 2006. Estimating the malaria risk of African mosquito movement by air travel. Malaria Journal, 5, 57. https://doi.org/10.1186/1475-2875-5-57

Thomas, S., Ravishankaran, S., Justin, N.A.J.A., Asokan, A., Mathai, M.T., Valecha, N., Montgomery, J., Thomas, M.B., Eapen, A. 2017. Resting and feeding preferences of Anopheles stephensi in an urban setting, perennial for malaria. Malaria Journal, 16:111. United Nations Conference on Trade and Development. (2021). Review of Maritime Transport 2020. United Nations.

USDA APHIS I History of Feral Swine in the Americas. (n.d.). Retrieved July 19, 2021, from https://www.aphis.usda.gov/aphis/ourfocus/wildlifedamage/operational-activities/feralswine/feral-swine-history

Robert, V., Macintyre, K., Keating, J., Trape, J.-F., Duchemin, J.-B., Warren, M., \& Beier, J. C. 2003. Malaria transmission in urban sub-Saharan Africa . The American Journal of Tropical Medicine and Hygiene, 68(2), 169-176. https://doi.org/10.4269/ajtmh.2003.68.169

World Health Organization. 1981. Instructions for determining the susceptibility or resistance of mosquito larvae to insecticides. WHO/VBC/81.807. 
World Health Organization. 2005. Guidelines for Laboratory and Field Testing of Mosquito

Larvicides WHO Pesticides Evaluation Scheme: WHO/CDS/WHOPES/GCDPP/2005.13, WHO, Geneva.

World Health Organization. 2016. Test procedures for insecticide resistance monitoring in malaria vector mosquitoes. Second Edition. 55pp.

World Health Organization. 2019. World malaria report 2019. Geneva, Switzerland: World Health Organization.

World Health Organization. 2019. Vector alert: Anopheles stephensi invasion and spread.

Geneva, Switzerland: World Health Organization.

World Health Organization. 2020. Malaria Threats Map. Invasive Vector Species. Accessed November 17, 2020

https://apps.who.int/malaria/maps/threats/?theme=invasive\&mapType=invasive\%3A0 \&bounds $=\% 5 B \% 5 B-107.68381650000767 \% 2 C-$

14.36364840304978\%5D\%2C\%5B74.42555849997683\%2C59.03306620140313\%5D\%5D\&in secticideClass=PYRETHROIDS\&insecticideTypes=\&assayTypes=MOLECULAR_ASSAY \%2CBIOCHEMICAL_ASSAY\%2CSYNERGIST-

INSECTICIDE_BIOASSAY\&synergistTypes=\&species=\&vectorSpecies=\&surveyTypes= \&deletionType=HRP2_PROPORTION_DELETION\&plasmodiumSpecies=P._FALCIPA RUM\&drug=DRUG_AL\&mmType=1\&endemicity=false\&countryMode=false\&storyMo de=false\&storyModeStep=0\&filterOpen=false\&filtersMode=filters\&years=1985\%2C2020

World Health Organization. 2020. World Malaria Report 2020. Geneva, Switzerland: World Health Organization.

Yared, S., Gebressielasie, A., Damodaran, L., Bonnell, V., Lopez, K., Janies, D., \& Carter, T. E. (2020). Insecticide resistance in Anopheles stephensi in Somali Region, eastern Ethiopia. Malaria Journal, 19(1), 180. https://doi.org/10.1186/s12936-020-03252-2 
Yee, D. A., Allgood, D., Kneitel, J. M., \& Kuehn, K. A. 2012. Constitutive Differences between Natural and Artificial Container Mosquito Habitats: Vector Communities, Resources, Microorganisms, and Habitat Parameters. Journal of Medical Entomology, 49(3), 482-491. https://doi.org/10.1603/ME11227

\section{Abbreviations}

LSBCI - Liner Shipping Bilateral Connectivity Index

LASIMTI - Likelihood of Anopheles stephensi Introduction Through Maritime Trade Index HIS- Habitat suitability index

\section{Acknowledgements}

The authors would like to thank Jen Armistead, Tony Hughes, Audrey Lenhart, John Gimnig,

Melissa Yoshimizu, Peter Mumba, and Diana Iyaloo for providing valuable feedback on previous versions of the manuscript and Anne Wilson, Dave Weetman, Ayman Ahmed, and Tamar Carter for fruitful discussions on the approach.

\section{Consent for publication}

Not applicable

\section{Availability of data and material}

All data generated are included in this manuscript and supplementary files.

\section{Competing interests}

The authors declare that they have no competing interests. 


\section{Funding}

JA is funded by Emory University and the U.S. Centers for Disease Control and Prevention. SZ and SI are funded by the U.S. President's Malaria Initiative.

\section{Disclaimer}

The findings and conclusions in this report are those of the author(s) and do not necessarily represent the official position of the U.S. Centers for Disease Control and Prevention or the Department of Health and Human Services. 